DEMOGRAPHIC RESEARCH

VOLUME 40, ARTICLE 46, PAGES 1345-1374

PUBLISHED 28 MAY 2019

http://www.demographic-research.org/Volumes/Vol40/46/

DOI: 10.4054/DemRes.2019.40.46

Reflection

\title{
A decade of life-course research on fertility of immigrants and their descendants in Europe
}

\section{Hill Kulu}

Nadja Milewski

\section{Tina Hannemann}

\section{Júlia Mikolai}

This publication is part of the Special Collection on "Childbearing among the Descendants of Immigrants in Europe," organized by Guest Editors Hill Kulu and Tina Hannemann.

(C)2019 Hill Kulu, Nadja Milewski, Tina Hannemann \& Júlia Mikolai.

This open-access work is published under the terms of the Creative Commons Attribution 3.0 Germany (CC BY 3.0 DE), which permits use, reproduction \& distribution in any medium for non-commercial purposes, provided the original author(s) and source are given credit.

See http:// creativecommons.org/licenses/by-nc/2.0/de/ 


\section{Contents}

1 Introduction 1346

2 Review 1347

2.1 The 'success story' of the life-course approach to migrant fertility 1347

2.2 Recent research on childbearing patterns among immigrants and 1351 their descendants in Europe

$3 \quad$ Papers of the special collection 1354

$4 \quad$ Conclusions and future research avenues 1358

4.1 Methodological challenges to study immigrant fertility 1359

4.2 Descendants of immigrants: Acculturation vs. subculture and 1364

$5 \quad$ Acknowledgements 1367

$\begin{array}{ll}\text { References } & 1368\end{array}$ 


\title{
A decade of life-course research on fertility of immigrants and their descendants in Europe
}

\author{
Hill Kulu ${ }^{1}$ \\ Nadja Milewski ${ }^{2}$ \\ Tina Hannemann ${ }^{3}$ \\ Júlia Mikolai $^{4}$
}

\begin{abstract}
OBJECTIVE

This article provides an introduction to a special collection on childbearing among the descendants of immigrants in Europe. We first review recent life-course research on fertility of immigrants and their descendants followed by a summary of the papers of this special collection. Finally, we discuss their contribution and future research avenues.
\end{abstract}

\section{RESULTS}

The papers of this special collection report significant heterogeneity in childbearing patterns among descendants of immigrants. Some groups have fertility levels similar to those of natives, some have lower fertility, and some exhibit significantly higher fertility. Further, polarisation characterises many descendant groups; some individuals have small families or even remain childless, whereas others have large families.

\section{CONCLUSIONS}

We conclude that factors related to mainstream society, minority subculture, and minority status all shape fertility behaviour of the descendants of immigrants and that their impact varies across descendant groups. Future research should investigate whether the observed heterogeneity in childbearing patterns is likely to decline over generations or the diversity is here to stay.

\footnotetext{
${ }^{1}$ University of St Andrews and ESRC Centre for Population Change, UK. Email: hill.kulu@st-andrews.ac.uk.

${ }^{2}$ University of Rostock, Germany.

${ }^{3}$ University of Manchester, UK.

${ }^{4}$ University of St Andrews and ESRC Centre for Population Change, UK.
} 


\section{Introduction}

Immigrant fertility emerged as an important research topic in Europe at the end of the $20^{\text {th }}$ century due to growing shares of immigrants and their descendants. Hence, the heterogeneity of the Western European populations has increased with regard to sociocultural and ethnic differences between the natives and immigrants. Some authors have called for a 'third demographic transition' as different subgroups seem to maintain distinct demographic behaviours (Coleman 2006). Others have emphasised the political and cultural distinctness within immigrant populations (Vertovec 2004). With a growing awareness of demographic heterogeneity, information to distinguish immigrants and their descendants has been included in official data sources as well as in social surveys (see Simon and Piché 2012). Further, studying immigrant fertility has a broader relevance for understanding contemporary fertility patterns in industrialised countries. The discussion of the role of economic, cultural, and structural factors is central both in research on overall fertility and immigrant fertility specifically (Kulu and González-Ferrer 2014).

Still, the number of studies that focus on demographic behaviour of immigrants was rather small until recently. For health and mortality research this may not be surprising as the immigrants who arrived in Western Europe in the 1950s and 1960s were reaching retirement age only at the beginning of the new century (Khlat and Darmon 2003; Kibele, Scholz, and Shkolnikov 2008; Sole-Auro and Crimmins 2008). In family research, studies examined factors that influence the spread and stability of interethnic marriages (Coleman 1994; Dribe and Lundh 2012; Goldscheider, Goldscheider, and Bernhardt 2011; González-Ferrer 2006; Kalmijn and van Tubergen 2006; Milewski and Kulu 2014). For fertility research, two trends can be observed. First, a small number of studies focused on aggregate-level fertility indicators, such as the total fertility rate (TFR) (e.g., Toulemon 2004) and their contribution to the overall TFR (e.g., Sobotka 2008). Others analysed the quantum of fertility using summary measures, such as completed cohort fertility (e.g., Mayer and Riphahn 2000). This research largely paralleled the approach used in studies in North American literature, where research on aggregate-level fertility among immigrants and ethnic/racial minorities has a long tradition. Second, a large body of research has emerged since the 2000s that investigates fertility behaviour at the individual level, applying a life-course perspective to family formation and subsequent births to immigrant mothers (e.g., Andersson 2004; Milewski 2007). This approach has dominated research of immigrant fertility in Europe over the last decade or so.

The aim of this article is to review recent life-course and longitudinal research on immigrants' and their descendants' fertility in Europe, its achievements, and the remaining open questions, which provide opportunities for further research. The paper 
also provides a concise overview of seven countrywide case studies included in this special collection: France, the United Kingdom, Belgium, Sweden, Spain, Switzerland, and Estonia.

\section{Review}

\subsection{The 'success story' of the life-course approach to migrant fertility in Europe}

A decade ago Kulu and Milewski (2007: 567) argued "that the life-course approach and event-history analysis offer a fruitful framework to examine how individuals simultaneously structure their family lives and residential trajectories, and thus shape demographic change in society." At that time, research on migrant fertility was mainly driven by household-economic considerations based on neoclassical economics, and analyses were mainly carried out at the macro level (Coleman 1994). The association between spatial mobility and fertility at the individual level was mostly investigated in the context of internal migration, be it from rural to urban areas or in the context of suburbanisation (Mulder and Wagner 2001). The life-course approach, going back to the Chicago school about a century ago, was adopted by demographers to study the social embeddedness of individuals' demographic behaviour. The aim was to improve our understanding of demographic and social change at the population level and differences between subpopulations. The approach was related to two ideas: first, the methodological individualism that posits that social phenomena emerge from individuals' actions (Elster 1989; Hollis 1996: 358) and, second, the dynamic approach to human agency, social relations, and context when explaining individual action (see Bourdieu 1977; Giddens 1984). Taking these ideas together, the life-course approach (Giele and Elder 1998) in the study of human fertility means that the focus is on the timing of events (i.e., births by order) and their interrelationships with changes in other life domains of individuals, changes in social relations, and societal context.

International migration is an event that affects each life domain of individuals and their social relations. Therefore, previous research on migrants' fertility behaviour focuses on the association between migration and childbearing. Over the past ten years, three review papers were published on the topic (Adserà and Ferrer 2015; Kulu and González-Ferrer 2014; Kulu and Milewski 2007). Therefore, we focus on the main research perspectives and selected recent papers rather than summarise the results of each study published in the past decade. As the event of international migration affects those who moved, most of the studies focus on immigrants or foreign-born individuals. Five main hypotheses were brought forward, which are not mutually exclusive and work with the assumption that the fertility behaviour of migrants may be different 
compared to that of the majority population as a consequence of the migration process and the related opportunities and constraints. The socialisation hypothesis states that the preferences that shape important life decisions, such as the timing of parenthood and family size, are developed early in life and shaped by the social environment during youth and young adulthood. For immigrants, this means that preferences and family models from the country of origin play an important role when family formation decisions are made in the host country after migration. The adaptation hypothesis argues that with time, immigrants' behaviour, including demographic events such as the onset of parenthood and completed family size, will converge to the behaviour of the natives (Andersson 2004; Kulu 2005; Milewski 2007; Singley and Landale 1998). Therefore, immigrants who arrived at young ages in the host country and spend many years under the influence of the destination society might exhibit fertility behaviour more similar to that of natives than recently arrived immigrants or individuals from origin countries, which differ greatly from the host society in social norms, beliefs, culture, and behaviour.

The selection hypothesis assumes that the destination country is selected (consciously or unconsciously) by migrants to fit their individual life expectations and aspirations (Hoem 1975; Kulu 2005; Macisco, Bouvier, and Weller 1970). This could include education, occupation, cultural beliefs, or family models. Individuals with characteristics close to those in the host country, which are not representative of their country of origin, might be more prone to migrate. Therefore, what might look like a rapid adaptation process might merely be a continuation of individual preferences on family formation choices. The disruption hypothesis emphasises the disruptive nature of the migration event on family dynamics. Moving from one country to another is often preceded by long-term preparations and proceeded by an acculturation phase, which consumes much of the available time and resources and therefore may disrupt any family formation plans until the immigrant has established herself economically, socially, and culturally in the host country (most studies focus on women). For couples, the migration process may coincide with a period of spatial separation. By contrast, the interrelation of life events hypothesis assumes that migration coincides with other changes in family dynamics, such as union/household formation, marriage, and family reunion (Andersson 2004; Kulu 2005; Milewski 2007).

These five hypotheses were mainly tested in studies in one country, comparing immigrants to the majority populations as a point of reference. The implicit research paradigm is the classical assimilation perspective (Gordon 1964), whereby immigrants are assumed to become similar over time and across generations to the majority population at destination. Recent approaches investigate the role of the receiving societal context in shaping integration processes by comparing one origin group at different destinations (Milewski 2011). Another research avenue compares emigrants to 
stayers at the country of origin (Baykara-Krumme and Milewski 2017); this offers a better way of answering the question of how the migration process impacts subsequent fertility behaviour because migrants and stayers originate from the same (and therefore comparable) populations (which is not the case in the immigrant versus stayers at the destination setting). In addition, the comparison between emigrants and stayers at the origin country allows a separation of the effects of migration from cultural aspects.

The childbearing behaviour of the descendants of immigrants (the second generation) is influenced by the social environment in the country where they grew up. However, the living environments of different groups of descendants of immigrants may differ significantly. Some of the second generation may grow up under the influences of mainstream society and are thus socialised into the norms and behaviours of the native population. By contrast, others may grow up under the influences of a minority subculture (assuming that such a subculture exists) and thus exhibit fertility preferences and behaviour that differ from those of the native population (Kulu and González-Ferrer 2014; Kulu and Hannemann 2016; Milewski 2010a, 2010b). Socialisation into a minority subculture is sometimes referred to as the subculture hypothesis, which is used to explain higher fertility among the descendants of immigrants from high fertility countries. According to this approach, members of an immigrant-origin subgroup may preserve values, norms, and behaviour concerning family and fertility that are common in the respective countries of origin (e.g., familialism). Therefore, fertility levels may be higher among the women of minority groups born and raised in the destination country than among women of the majority population, even when taking social characteristics into account (Milewski 2010b).

It is thus important to determine whether the fertility behaviour of the descendants of immigrants is similar to that of their parents or to the patterns that are dominant in mainstream society. If immigrants and their descendants exhibit similar fertility behaviour, which differs significantly from that of the native population, we can assume that the influence of a minority subculture was dominant in their fertility behaviour. By contrast, if we observe similar patterns for the second generation and the natives, we could conclude that the descendants of immigrants were mostly influenced by mainstream society. If both mainstream society and the minority subculture were important, the descendants of immigrants would, on average, exhibit fertility patterns that are in-between those of immigrants and natives (both with respect to the number of children and timing of births) (Kulu and González-Ferrer 2014).

Classical assimilation theory would suggest that migrant generations gradually adopt the attitudes and behaviours of the natives at the destination (Gordon 1964). However, the empirical evidence on several measures of integration does not show such a clear pattern (Alba and Foner 2015; Alba and Nee 2003). The second generation plays a crucial role in the processes of migrant integration because in their socialisation they 
can draw upon various resources: i.e., their parents' culture and that of the society at the destination country. Women and men in subsequent migrant generations need to navigate throughout their adulthood by choosing from or between elements of at least two cultural heritages under societal circumstances that may be in tension with these cultural traditions. Foner (1997) calls this process "bicultural adjustment." Previous literature tends to portray the second generation as being "exposed to competing pressures" (Berrington 2018; Kalmijn and Kraaykamp 2018) based on the assumption that the family of origin has more conservative values than the majority group in the destination country.

While there is no direct role of the selection effect for the second generation, preferences for higher education and employment could be transmitted from parents to children during their upbringing and consequently extend the selection effects beyond the initial generation. This would generate similar fertility behaviour among the second generation as in their parents' generation. The minority-group status hypothesis centres on psychological aspects and emphasises a fertility-depressing effect, as one of the traits that define a minority group is the experience of discrimination, which may lead to "feelings of frustration and marginality" (Milewski 2010b). The minority-group argument comes into play mainly if minority-group women of a certain educational level do not exhibit fertility levels that are similar to majority-group women of comparable levels of education. This can be seen as a result of discrimination, resulting from minority status. Due to economic considerations, several authors argue that the frustration argument especially applies to women of higher education and higher socioeconomic status in a minority group. It is argued that better-educated women aspire more to upward mobility than less-educated women, and upward mobility is harder to achieve among minority-group members than it is for people belonging to the majority. Hence, women who have achieved a relatively high socioeconomic position may be less likely to risk a decline in their life conditions by having a relatively high number of children and therefore reduce their fertility below the levels of women of a comparable socioeconomic position in the majority population (Milewski 2010b).

Although the minority-status argument has been mainly raised for women of higher socioeconomic status, it is possible to extend this concept to other women (and also men): In circumstances where subjective discrimination leads to a general feeling of uncertainty and frustration, fertility disruption may be the consequence, regardless of the relative socioeconomic position of a woman (or man). Although the influence of the membership in a minority group on fertility is negative in nature, resulting from discrimination and economic uncertainty, minority status may also increase fertility levels (Poston, Chang, and Dan 2006). Discrimination against minorities on the labour market may reduce their opportunities for social mobility and some women may decide to enter the so-called motherhood track, especially in countries where state policies 
promote women with children to stay at home. In general it seems, however, that a pronatalist influence of the minority-group status can hardly be distinguished from the subculture hypothesis since a minority group needs a 'vehicle' in order to transport norms and values, such as a religious institution (Milewski 2010b).

\subsection{Recent research on childbearing patterns among immigrants and their descendants in Europe}

Most research on immigrant fertility in Europe in the past decade has aimed to test one or several hypotheses on migrant fertility. One research stream has been inspired by past research on the interrelationship between migration and family formation (Andersson 2004; Kulu 2005; Milewski 2007), which showed elevated fertility levels for many female migrants in Europe after migration. This research stream has also challenged the uncritical use of aggregated fertility measures for studying migrant fertility, often used by national statistical offices (especially the period TFR). Immigrant total fertility may be high (Sobotka 2008) because of the composition of the immigrant group; the population at risk for calculating the total fertility may consist mostly of married women with short marriage durations (Robards and Berrington 2016; Toulemon 2004).

While most previous research came from Western and Northern European countries, recent research also examines migrant fertility patterns in Southern European countries. Castro-Martín and Rosero-Bixby (2011) examine childbearing patterns of immigrants in Spain and show that immigrant women from North Africa experienced a peak of high fertility after arriving in Spain, especially if they moved for family reasons or if they were married before migration. Using Italian data, Mussino and Strozza (2012a) show that women who moved for family reasons had elevated fertility levels shortly after migration. Both studies demonstrated that employment-related migrants had different fertility patterns after migration than marriage-related migrants. Women who moved for work purposes had significantly lower fertility levels during their first years in Spain or Italy in comparison to other immigrant women. Similar patterns were also reported by Mussino et al. (2015) in their study on fertility of immigrants in the Lombardy region of Italy. A study by Persson and Hoem (2014) on Sweden is another good example demonstrating significant fertility differences between marriage-related migrants and other migrants. Fertility levels were significantly elevated after migration for immigrants from low-income non-European countries, suggesting that family formation was the main reason for their migration. In contrast, female immigrants from the Nordic countries exhibited low fertility levels after arrival but increasing levels of 
fertility over time, suggesting that many Nordic immigrants had moved to study or work in Sweden and only established a family later.

First-birth patterns are thus much shaped by the reason for migration (marriage versus work/education). Recent studies have also investigated second- and third-birth levels to determine how factors related to origin and destination countries influence immigrants' childbearing patterns. Milewski (2010a, 2010b) shows that in Germany second- and especially third-birth rates were relatively high for immigrant women from Turkey after controlling for socioeconomic factors, which the author attributed to socialisation factors. Mussino and Strozza (2012b) arrive at a similar conclusion; the analysis of second-birth rates among immigrants in Italy shows that immigrants from North Africa, particularly those who were in endogamous marriages (co-ethnic partners), had relatively high second-birth rates. Lillehagen and Lyngstad (2018) investigate third-birth rates in Norway and show that immigrant mothers from Pakistan, Turkey, Somalia, and Morocco exhibited a significantly higher likelihood of having a third birth than native Norwegian women. Their analyses also indicate that the sex preferences of immigrants matched those documented for their origin population, especially in case of son preference, supporting theories emphasising cultural persistence in preferences.

Previous research has shown that the descendants of certain immigrant groups have fertility levels and patterns similar to those of the native population, while other ethnic minorities, mostly of non-Western origin, display relatively early childbearing and high fertility levels (Sobotka 2008). Milewski (2007, 2010a) investigates the fertility of the second generation in Germany. The analysis showed similar fertility behaviour of immigrants from Southern European countries to that of native Germans, whereas the descendants of immigrants from Turkey showed distinct fertility patterns; they had an earlier transition to parenthood than native Germans and only a small proportion of women remained childless. Those of Turkish origin also exhibited a high propensity to have three children, indicating a preference for large families. Milewski (2011) also investigates the fertility of the descendants of immigrants from Turkey in a number of European countries. Women of Turkish origin had relatively high first-birth rates in all studied countries, but they exhibited somewhat lower first-birth rates in Germany and Switzerland than in France, the Netherlands, and Sweden. The study provided evidence for both socialisation into a 'minority subculture' and adaptation to the mainstream European societies. Scott and Stanfors (2011) arrive at similar conclusions in their study of the fertility of ethnic minorities in Sweden. The descendants of immigrants from high-fertility countries (e.g., Turkey, Lebanon, and Syria) had significantly higher first-birth levels than native Swedes, whereas descendants of immigrants from other European countries showed fertility levels either lower than or similar to native Swedes. 
A study by Coleman and Dubuc (2010) on the fertility patterns among ethnic minority women in the United Kingdom shows that the total fertility significantly declined among ethnic minority populations in the last decades of the $20^{\text {th }}$ century. Further, the total fertility of the descendants of immigrants was lower than that of immigrant women born outside the United Kingdom. However, fertility levels were low among women of Indian and black Caribbean descent, whereas fertility was relatively high among women of Pakistani and Bangladeshi origin. Recently, Wilson and Kuha (2018) also report high fertility among the descendants of Pakistani and Bangladeshi immigrants, which they attributed to the factors related to childhood socialisation in residentially segregated ethnic communities. Berrington (2018) shows that among the 1960-1979 cohorts who were born in the United Kingdom, 73\% of Pakistani women and $85 \%$ of Bangladeshi women had become mothers by age 30, as compared with only $60 \%$ of white British women. The results also suggest a significant delay and less ethnic diversity in the timing of entry into motherhood among more recent cohorts. This is explained by their educational aspirations and the postponement of childbearing among all groups, even among Pakistani and Bangladeshi young women.

Many previous studies focus on high fertility (by European standards), especially third-birth rates among certain ethnic minorities and their cultural and economic determinants, whereas recent studies have also reported relatively low fertility levels among some groups of immigrant descendants. Krapf and Wolf (2015) compare the fertility of Turkish immigrants who moved as children (the 1.5 generation) and of the second generation to that of native Germans. Women of Turkish origin who moved as children had significantly higher first- and second-birth rates than native Germans; fertility levels of the second generation were in-between. These findings were largely consistent with those observed by Milewski (2010a, 2011). Interestingly, however, further analysis shows that highly educated women of Turkish origin exhibited firstand second-birth rates similar to those of native Germans. Dupray and Pailhé (2018) observe low first-birth rates for the descendants of immigrants from North Africa in France. Women of North African descent had a first child later than native French women, which the authors attributed to employment uncertainty and the high level of unemployment among immigrants. These recent studies have thus shown that the fertility levels of the descendants of immigrants from high-fertility countries are usually lower than that of their parents, but for some non-Western groups, fertility levels remain relatively high in comparison to the native population. Studies also report the postponement of parenthood and relatively low fertility levels among some ethnic minority women, especially among those who are highly educated. 


\section{Papers of the special collection}

This special collection (SC) includes seven case studies across Europe; the countries are France, the United Kingdom, Belgium, Sweden, Spain, Switzerland, and Estonia. This selection of countries covers all the major regions of Europe. In most cases research includes immigrants and their descendants. Descendants of immigrants are defined as those who were born in the respective countries and have at least one foreign-born parent. The papers build on previous research on immigrant fertility and develop research further. First, all papers focus on fertility among the descendants of immigrants (or immigrants who arrived as children), comparing their childbearing patterns to those of immigrants and the respective native populations. Second, all studies apply similar methodology to comparable longitudinal data sets; they study fertility by birth order using event-history analysis techniques.

Pailhé (2017) compares the fertility of descendants of immigrants to that of native women in France by analysing the transition to first, second, and third births among the descendants of immigrants from the Maghreb region, sub-Saharan Africa, Turkey, and Southeast Asia. Little is known about the fertility behaviour of the second generation in France because previously, existing data did not allow to identify these individuals in large enough samples to compare behaviours across groups of origins (Simon 2008). Using data from the Trajectories and Origins Survey (2008), which oversampled immigrants and their descendants to study their living conditions and social trajectories, the author studies the fertility transitions of the second generation. She finds that the fertility behaviour of most groups of descendants of immigrants is converging towards that of native French women, although this convergence varies by group of origin. Women with Southeast Asian backgrounds have lower fertility and postpone motherhood compared to other groups of the second generation and even to native French women. However, their timing and levels of second births are similar to that of other women. Women of Turkish origin enter motherhood earlier and have higher firstand second-birth rates than native French women. Nonetheless, once compositional differences are controlled for (especially cultural factors such as the language spoken at home and the number of siblings), these differences disappear. Descendants of subSaharan immigrants tend to postpone first and second births; they form unions later and adopt the French model of late childbearing and comparatively small family size. The descendants of Maghrebian immigrants show the largest convergence to the French fertility patterns. The study also shows that in France, a higher level of education is a crucial factor in fertility differences between groups; first-birth risks converge across groups of origin for women with tertiary levels of education but differ among the less educated. 
Previous literature in the United Kingdom has established that women from some ethnic minority groups have higher fertility compared to natives (Coleman and Dubuc 2010). It has remained unclear, however, whether the reasons for this are cultural or economic. Kulu and Hannemann (2016) compare the fertility of immigrants and their descendants (i.e., those who were born in the United Kingdom but have at least one parent who was born outside the United Kingdom) to that of the native population of the United Kingdom using data from the Understanding Society study (University of Essex 2018). This is a large-scale panel survey (launched in 2009) that contains retrospective information on partnerships and fertility and has oversampled the five largest ethnic minorities, thus enabling the authors to conduct a detailed analysis on the behaviours of immigrants and their descendants. Previous studies in the United Kingdom focus solely on differences in aggregate-level fertility between natives, immigrants, and their descendants. This is the first study which calculates parityspecific fertility rates to detect the underlying fertility behaviour of ethnic minority women. The authors show that, indeed, many immigrant groups (especially those from Pakistan and Bangladesh) have higher fertility than the native population in the United Kingdom. Descendants of immigrants have lower fertility rates than immigrants from the same origin country. However, for some groups fertility levels are relatively high. Analysing fertility differences between native women and descendants of immigrants by parity reveals that fertility differences stem from high third- and fourth-birth rates among Pakistani and Bangladeshi women born in the United Kingdom, but there is little variation in first- and second-birth risks between the groups. After controlling for individuals' socioeconomic characteristics (such as employment and education) and cultural factors (English language proficiency, religiosity, number of siblings, and sex of previous child), fertility differences are reduced but persist. The authors conclude that it is unlikely that high fertility among women of Pakistani and Bangladeshi origin are due to economic factors. Instead, their relatively high fertility is related to cultural and normative factors, including religiosity and the size of the family of origin.

Van Landschoot, de Valk, and van Bavel (2017) study the fertility behaviour of descendants of immigrants in Belgium. Whereas most previous studies have focused on women's characteristics, this study introduces the importance of the characteristics of the male partner. Most importantly, they focus on whether the partner is of the same (endogamous) or different (exogamous) ethnic origin and whether the male partner was a first-, 1.5, or second-generation immigrant. Using data from the 2001 Belgian Census linked with the 2006 Belgian National Population Register, the authors analyse differences in second- and higher-order birth rates of women belonging to the second generation in Belgium by ethnic origin and migration history (i.e., different generation of migrants) of the male partner. They distinguish between women of Southern European, Turkish, and Moroccan origin. When comparing fertility patterns of the 
second generation and native Belgian women, they find that women of Southern European origin have lower birth rates, whereas those of Moroccan and Turkish origin have higher rates of second and subsequent births than native women. With respect to the partner's characteristics, this study shows that women of Turkish and Moroccan origin in endogamous unions have higher rates of second and subsequent births than those who are in an exogamous union (i.e., with a native Belgian man). The study demonstrates the importance of the spouse's background in explaining the transition to a second or higher birth.

Andersson, Persson, and Obućina (2017) focus on the childbearing behaviour of women of the second generation in Sweden, a country with relatively high levels of immigration, near-replacement-level fertility, and policies aimed at social equality. Using register data (1998-2012) and event history models, the authors study the transition to first, second, and third births among twenty origin groups of the immigrant descendants, adjusting for their socioeconomic characteristics. The largest group of descendants of immigrants has at least one parent from Finland; the second largest group are those whose parents are from other Nordic countries (e.g., Denmark, Norway, and Iceland), and the third largest are those of Western European origin. The authors show that most second-generation groups have lower fertility than the Swedish natives. Descendants of immigrants are especially less likely to have a first birth than those who have two Swedish-born parents. The relative risk of a second birth among mothers who had a first child is also lower among almost all second-generation groups. However, many descendants of immigrants who had a second child display elevated levels of third-birth risks. There are several possible reasons for the depressed first- and secondbirth rates among some groups. On the one hand, relatively low second-birth rates may be due to lower responsiveness of immigrants and their descendants to the speed premium' policy of the Swedish parental-leave system. On the other hand, low fertility rates may reflect unrealised fertility intentions because of the challenges that young adults from minority families face when seeking to establish themselves as adults and to start a family.

González-Ferrer et al. (2017) study the fertility of immigrants and their descendants in the context of Spain, a country with one of the lowest levels of fertility in Europe and a rather young mass-immigration history. Using fertility histories from the Fertility and Values Survey (2006) for natives and from the National Immigrants Survey (2007) for immigrants, the authors analyse the transition to first, second, and third birth among immigrants, the 1.5 generation (i.e., respondents who have migrated to Spain before age 16), and native Spanish women. Overall, migrant women (except those coming from industrialised countries of Europe, the United States, and Canada) have higher first-birth rates than Spanish-born women. This is interpreted as differences in the timing of first births rather than in the levels (as childlessness is relatively 
uncommon among all women). However, migrants' transition rates to a second birth are lower compared to native women (except for women born in the Maghreb countries). When the authors restrict the analysis to women who were childless when they migrated to Spain, all immigrant women, except those from other industrialised countries, delay the transition to first birth to even later ages than native Spanish women. Women from the 1.5 generation display more mixed patterns; those from the Maghreb countries have higher second- and third-birth rates than Spanish women, whereas those from Latin American origin have similar fertility patterns to native Spanish women.

Guarin Rojas, Bernardi, and Schmid (2018) study first- and second-birth rates among immigrants and their descendants in the multilingual context of Switzerland, where the immigrant population consists of traditional (from Italy, Spain, France, Germany, and Austria) and new groups (from Portugal, Turkey, and former Yugoslavia). In Switzerland, 36\% of the population is of immigrant origin and the different immigrant groups are very diverse in terms of geographical origin, socioeconomic status, and migration trajectories. Based on previous studies, surprisingly little is known about first- and second-birth risks of immigrant groups in Switzerland, especially among the descendants of immigrants and among new groups of migrants from Turkey, Portugal, and the Balkan region. Previous studies on migrant fertility in Switzerland have studied fertility by nationality instead of focusing on different immigrant groups by origin or different generations of immigrants. Using data from the Family and Generation Survey (2013), the authors compare the fertility of migrants and their children to that of the native Swiss population by parity (i.e., first and second births), controlling for a range of socioeconomic and demographic factors. They find that immigrants from Eastern and Southern Europe have higher first-birth risks than the second generation and natives. Additionally, descendants of immigrants have lower first-birth risks than their parents and Swiss natives (except those from Eastern and Southern Europe). Immigrants and their descendants have lower secondbirth risks than Swiss natives, which the authors attribute to the country's strict family reunification policies (and the lack of extended families), relatively poor public support for parents, and high costs of childrearing in Switzerland.

Previous studies on the fertility of immigrants and their descendants have focused on Western, Northern, and Southern European countries; much less is known about the fertility patterns of immigrants and their descendants in Eastern Europe. Puur et al. (2017) compare the fertility patterns of first- and second-generation Russians in Estonia to that of native Estonians and Russians in the sending country using retrospective data on partnerships and fertility from both the Estonian and the Russian Generations and Gender Surveys (2004-2005). Additionally, this study explores the role of the educational system and spatial concentration of migrants, which are rarely considered in 
the literature. Ethnic Russians are the largest immigrant group in Estonia; since the 1990 s, they constitute about one-fourth of the total population. Around $38 \%$ of Russians in Estonia are immigrants and the remaining $62 \%$ are their descendants. The authors find that first-birth risks of Russians in Estonia are in-between that of Russians in Russia and native Estonians. These differences are driven by differences in the timing of childbearing. When comparing immigrants from Russia and their descendants in Estonia, a consistent trend is observed whereby first-birth risks of the second generation show some convergence to that of native Estonians. However, migrants and their descendants in Estonia have a lower propensity to have a second and third birth than native Estonian women. Thus, the fertility behaviour of Russians in Estonia is more similar to that of the population at the origin country than to the host population. However, those who have parents of mixed Estonian-Russian background, were enrolled in Estonian-speaking schools, and lived in areas where the host population resides have shown a convergence in their childbearing behaviour to that of the host country.

\section{Conclusions and future research avenues}

This special collection (SC) consists of seven case studies on the fertility of the descendants of immigrants by comparing their patterns to those of immigrants and the respective native populations. All case studies use large-scale longitudinal data and apply event-history analysis to parity-specific fertility. The analyses show that most descendants of immigrants have relatively low first-birth rates (i.e., similar to that of natives), suggesting the postponement of childbearing (also) among ethnic minorities. The only exception are women of Turkish origin, who exhibit elevated first-birth levels in several countries (Sweden, Switzerland, Belgium, and France), indicating early childbearing among this group. Some ethnic minority groups have somewhat higher second-birth risks than the respective natives (e.g., women from South Asia in the United Kingdom and from Morocco in Spain), whereas others have second-birth rates similar to the respective natives or even lower. Many descendants of immigrants show significantly higher third-birth rates: Elevated third-birth levels are observed among Turkish, Middle Eastern, and North African women in Sweden; South Asians in the United Kingdom; and North Africans in France, Belgium, and Spain. Elevated thirdbirth levels largely explain a relatively high total fertility among these minority groups. Fertility differences between native and ethnic minority women largely persist once women's educational level is included in the analysis but decrease after factors related to language, religion, and the size of family of origin are controlled for. 
The studies show that childbearing patterns vary significantly among the descendants of immigrants in European countries. Some groups show fertility behaviour similar to natives. These are often descendants of immigrants from neighbouring European countries. It is possible that their childbearing patterns are similar to those of natives because their parents come from countries with similar fertility levels. However, many immigrants are married to natives, which suggests that mainstream society has shaped fertility intentions and behaviours of their descendants. Some descendant groups have lower fertility than the natives in their respective countries (e.g., Southern Europeans in Western Europe, Russians in Estonia, and Iranians in Sweden). Again, their fertility patterns may be related to those of their parents' country of origin (e.g., for Southern Europeans). On the other hand, they may (also) reflect unmet demand for children and unrealised fertility intentions. The reason for this may be the challenges that young adults from minority families face when seeking to establish themselves as adults and to start a family (Kulu et al. 2017). These findings support the notion that minority status plays an important role in childbearing behaviour. Finally, descendants of immigrants from high-fertility countries have higher fertility than the respective natives, although the studies also showed some polarisation among them. There is a small group of those who have their first child as late as native women or even remain childless, while many have relatively large families (i.e., three or four children, similarly to their parents' generation). Clearly, their high fertility is related to their family of origin (e.g., number of siblings and religiosity) and the role minority subculture has played in their socialisation. Many of them have immigrant parents and were brought up in ethnic communities.

\subsection{Methodological challenges to study immigrant fertility}

Research on immigrants' and their descendants' fertility has progressed significantly in the last few decades. First, most studies have moved beyond conventional aggregate fertility measures (age-specific fertility rates and the total fertility rate) by investigating immigrant fertility by birth order, which is necessary to detect the underlying fertility behaviour of individuals (Kulu and Hannemann 2016). This trend is largely consistent with the wider developments in fertility research in which fertility analysis by birth order has become a norm (Hoem 1990, 1993 for fertility research; Andersson 2004 and Milewski 2007 for international migrants; Kulu 2005 for internal migrants). Parityspecific analysis also characterises the papers of this SC. Second, most studies have included duration since migration in the analysis and have calculated parity-specific fertility rates by time since immigration. This approach has allowed researchers to 
better test competing hypotheses on immigrant fertility, e.g., interrelated events versus disruption or socialization versus adaptation.

However, after a decade of using disaggregated fertility measures in research on migrant and ethnic minority fertility, there is still a continued need to calculate some summary measures, particularly from a period perspective, and revisiting the conventional aggregate measures in light of the findings from life-course research may be justified. While the use of the TFR to investigate fertility of the second generation does not raise any issues, the measure poses challenges when we wish to study immigrant fertility. The TFR for immigrant women is often relatively high, sometimes even if calculated for women from low-fertility countries. Previous research relates elevated migrant fertility either to the interrelationship between migration and family formation - many women move to form a family, as the studies of this SC show - or to tempo effects distinguishing between pre-migration low fertility and post-migration high fertility (Milewski 2007; Robards and Berrington 2016; Toulemon 2004).

Many recent studies recommend a careful use of the TFR for immigrants, and some suggest that the TFR as a synthetic cohort measure should not be used at all since the immigrant TFR does not reflect the underlying lifetime propensity to have children and it is unclear what the hypothetical population is for the immigrant TFR (Murphy 2016; Robards and Berrington 2016). While we agree with the criticism by previous research, we argue that aggregated fertility measures can be used, but as with parityspecific rates, duration since immigration should be explicitly considered. Robards and Berrington (2016) have calculated age-specific fertility rates for immigrants by years since migration. We suggest that duration-specific fertility rates (or parity-specific fertility rates by duration) can be summed up to produce the duration-based TFR, or TFR $d$, for immigrants as a summary measure. The idea is not new - it is inspired by the criticism of the conventional total marital fertility rate (TMFR) (Hinde 1998) and the duration-based TMFR proposed by Hoem and Mureşan (2011). Next, we illustrate the usefulness of the duration-based TFR for immigrants for the United Kingdom using data from the Understanding Society study (1991-2008).

In Figure 1, the dark bars show the age-based TFR of immigrants and their descendants (as the average between 1991 and 2008); we have distinguished between those immigrants who arrived in the United Kingdom as adults (defined here as aged 15 and older) and those who were children at the time of their arrival (younger than age 15). First, we see that the TFR is high among immigrants from South Asia and relatively low among those who came from continental European countries; immigrants from other countries hold an intermediate position. Second, fertility levels among those who arrived in the United Kingdom as children and the descendants of immigrants are significantly lower than those for immigrants, but for some groups (e.g., South Asians), the levels are relatively high (by European standards). However, as previous research 
has shown, the use of the age-based TFR for immigrants may have little meaning if the nature of the immigration process is not considered because the age-based approach does not account for elevated fertility levels after migration.

\section{Figure 1: TFR and TFR $d^{5}$ of immigrants, distinguishing among those who arrived as adults (1G, adult) or as children (1G, child), and their descendants (2G) in the United Kingdom}

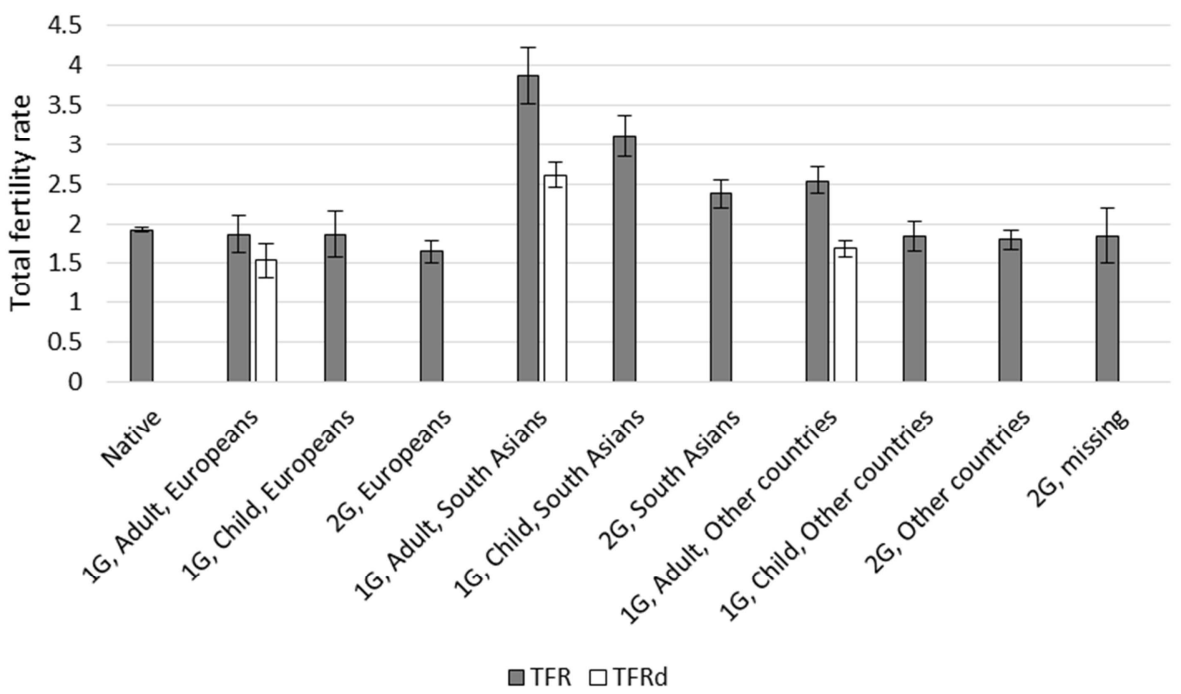

Notes: South Asian groups consist of women of Indian, Pakistani, and Bangladeshi origin. Immigrants are individuals who were born abroad; " $1 \mathrm{G}$, Child" is defined as immigrants who arrived in the destination country before age 15; " $2 \mathrm{G}$, missing" includes individuals who are known to be descendants of immigrants but their parents' country of birth is unknown.

Source: The authors' own calculations based on data from the Understanding Society study.

As previous research shows, the fertility of immigrants depends on time since migration. Figure 2 reports fertility rates by time since migration and age at migration for immigrants who arrived to the United Kingdom as adults (i.e., the first generation). Clearly, for most age groups birth rates are the highest during the first three years after migration and decline by duration of stay. Fertility levels for those who arrived at age 15 to 19 are somewhat different; they increase with the duration of stay and reach their

${ }^{5}$ Duration-based TFR or TFR $d$ is calculated as follows: $T F R d=\sum_{0}^{35} D S F R$, where DSFR is durationspecific fertility rate. 
peak five to six years after migration. The pattern is largely explained by the fact that some of these immigrants were still children at the time of their arrival. Others may have migrated for education purposes. Figure 3 shows that fertility patterns by time since migration significantly vary across immigrants' region of origin among those who arrived as adults in the United Kingdom. While immigrants from South Asia exhibit elevated fertility levels after arrival, fertility levels are relatively low among those who came from other European countries and are somewhat elevated for immigrants from other countries. These patterns are reassuringly consistent with those found by Robards and Berrington (2016) using a different administratively linked data set, the ONS Longitudinal Study.

Figure 2: Fertility rate of immigrants by time since migration and age at arrival for those who arrived as adults (1G) in the United Kingdom

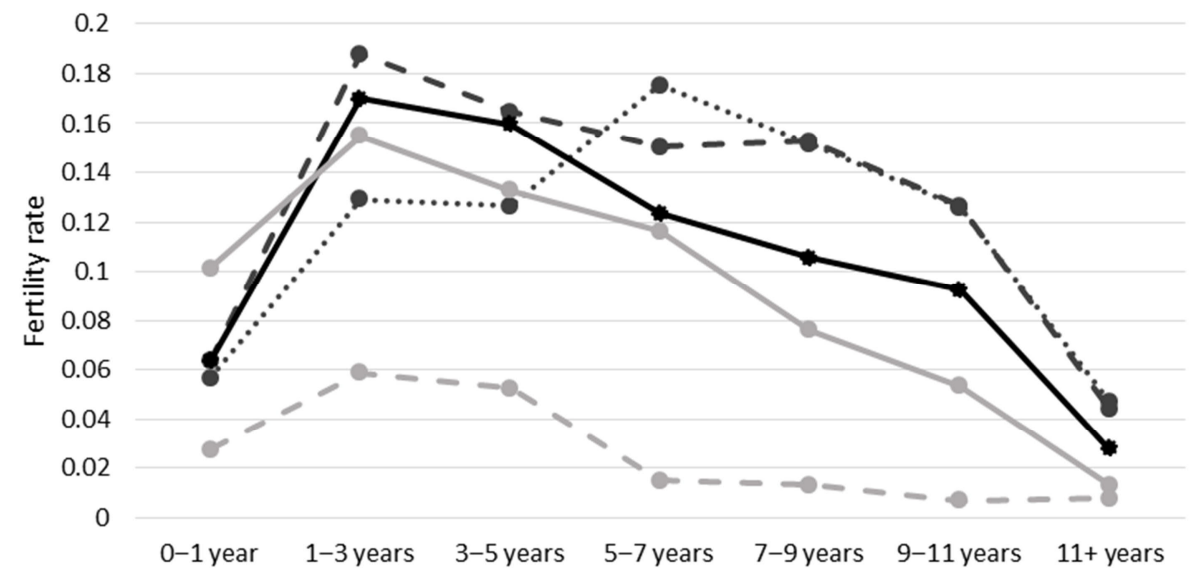

Time since migration

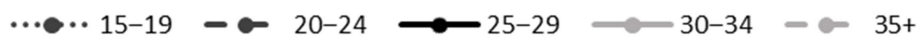

Source: Same as Figure 1.

Next, we calculate duration-based TFR, or TFR $d$, for immigrants in the United Kingdom (as the average between 1991 and 2008) by summing up duration-specific fertility rates (see Figure 1, light bars). We observe elevated fertility levels for immigrant women from South Asia, as expected; however, the levels are much lower than measured by the age-based TFR. Interestingly, the TFR $d$ among immigrants is lower than the TFR for child immigrants, which is similar to the TFR of the 
descendants of immigrants. A similar difference between the age-based TFR and the duration-based TFR is observed for immigrants from other countries, whereas there is little difference between the two measures for immigrants from other European countries.

Figure 3: Fertility rate of immigrants by time since migration and region of origin for those who arrived as adults (1G) in the United Kingdom

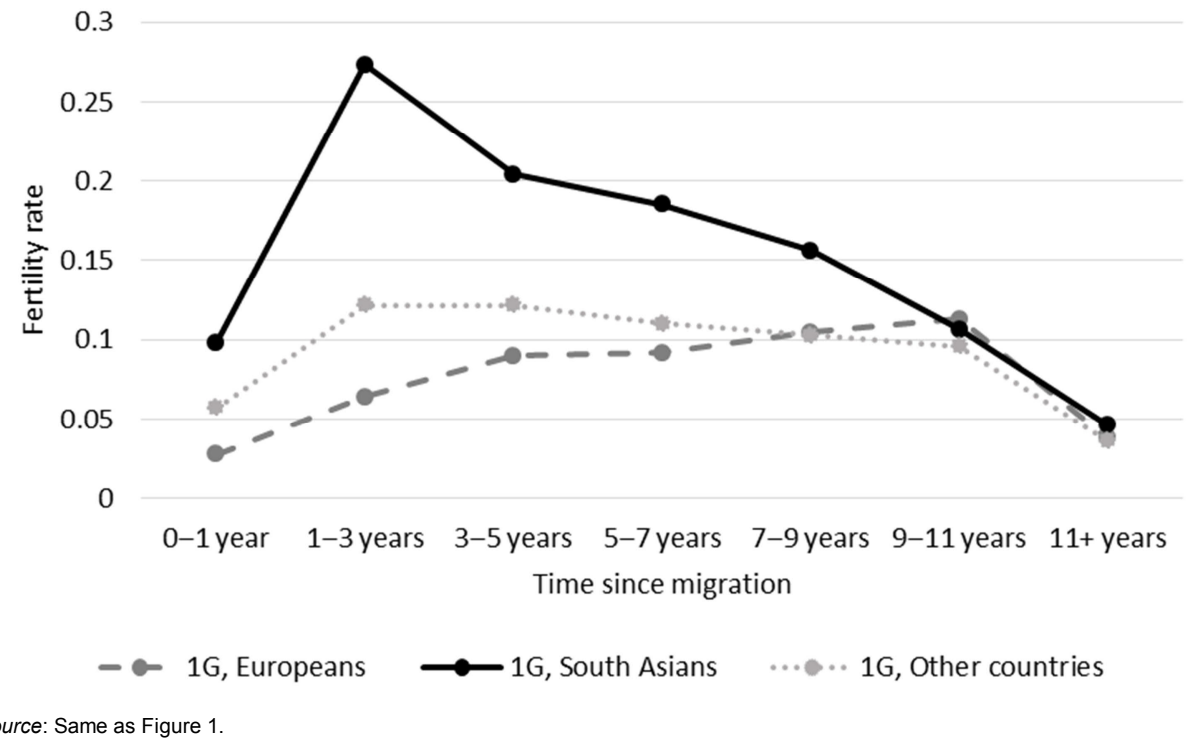

Finally, we calculate the duration-based TFR by age at arrival in the United Kingdom for immigrants who arrived as adults. The value of the TFR $d$ is the largest among those who arrived at a young age and the smallest among older arrivals (Figure 4). The values of the TFR $d$ are higher among South Asians than Europeans and immigrants from other countries, as expected. Interestingly, if we compare the TFR $d$ for immigrants who arrived at age 15-19 to the age-based TFR of those who arrived as children (0-14) (see Figure 1), we observe very similar values for all three groups supporting the idea that the TFR $d$ has a meaningful interpretation: the number of children born to an immigrant women if their childbearing proceeds according to the duration-specific fertility used to calculate the TFR $d$. The TFR $d$ thus provides a more realistic estimate of fertility levels among immigrants than the age-based TFR. The analysis also highlights that the TFR $d$ is the weighted average for immigrants with 
different ages at arrival and is therefore sensitive to the age composition of immigrants at the time of arrival.

Figure 4: Duration-based total fertility rate (TFRd) of immigrants by age at arrival for those who arrived as adults (1G) in the United Kingdom

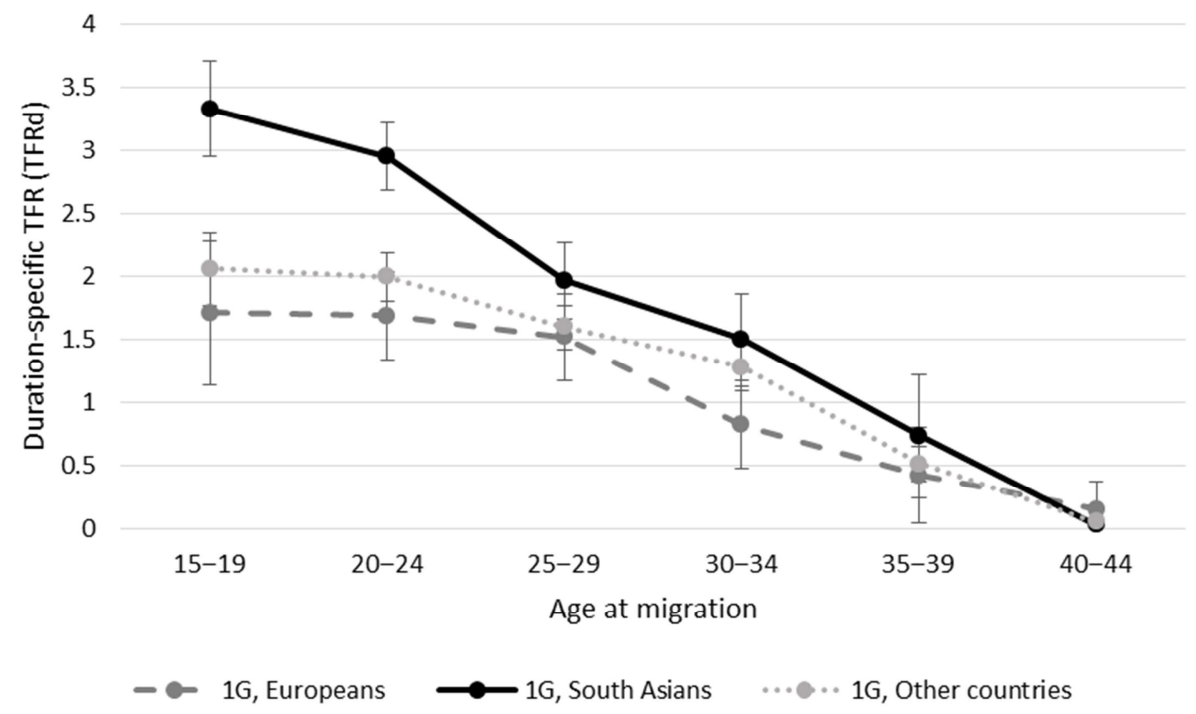

Source: Same as Figure 1.

\subsection{Descendants of immigrants: Acculturation vs. subculture and minority status}

The papers in this SC show that overall (across countries of destination and immigrant groups) the fertility patterns of migrant descendants vary relative to the first generation of their own origin group, relative to the natives at the destination country, and between origin groups. This variation is largely in line with previous literature and suggests that the topic of migrant fertility deserves continued scholarly attention not only in the second but also in subsequent generations. The main question for future research is why we observe this continuation of differences in demographic behaviour even in societal contexts, such as Sweden, which specifically aims to homogenise their population by promoting (gender) equality. In answering this question, we may be better able to make 
predictions about the continuation or change in the fertility behaviour of subsequent immigrant generations.

One of the crucial issues will be whether a certain immigrant group in a certain country develops into a minority group. Minority groups and immigrant groups may overlap or be distinct from each other, or a group of migrants may develop gradually into a minority group over time and generations (Coleman 1994; Haug 2000). Bean and Tienda (1990) list four criteria that characterise minority groups: (1) each of the subgroups constitutes only a small share of the total population of a country, (2) members of the particular group experience a sense of self-awareness as belonging to the group as its members, (3) members of the particular group experience a degree of discrimination by members of the majority group, and (4) the members of the particular group are to some extent discernible in their appearance as its members.

The criterion of physical appearance is mainly used in the debate in the United States, where it refers to classifications by skin colour (race). However, modifications of these criteria were applied to different contexts. Kennedy (1973) emphasises social cohesion between group members who share a religious affiliation in Ireland and Northern Ireland. Poston, Chang, and Dan (2006) use recognition by the government of specific nationalities (Minzu) as the criterion for defining minorities in China, where the members of the Minzu are hardly or not at all distinguishable by physical appearance from the majority population of China (Han). Previous literature on migrant fertility in Europe has hardly applied the minority-group framework (Milewski 2010b). Instead, previous studies use the 'usual suspects' in fertility research, which refer to socioeconomic factors. 'Culture' was mainly used as a kind of residual explanation in those cases where fertility differences between immigrants and natives or between different immigrant groups remained after controlling for socioeconomic characteristics.

Furthermore, the studies included in this SC indicate that socioeconomic factors matter in subsequent migrant generations and their role varies between different receiving contexts as well as between origin groups, which indicates that culture plays a moderating role. In order to tackle the question of structure versus culture in more detail, we first suggest that future research should make an effort to better define a 'minority group.' What is the criterion that makes a difference for fertility behaviour? It may not be the migrant status or the migrant generation because there are also groups whose fertility behaviour resembles that of the natives in the destination country. It may rather be a difference in religious affiliation, physical appearance, or the experience of discrimination (as brought forward by the minority-status hypothesis).

Second, cultural aspects should be included in the analysis of migrant minority fertility. One of these aspects is whether a birth occurs within marriage. In (Western) European contexts, marriage has lost its dominant position in being the only setting for 
childbearing. Many immigrant groups to Western Europe originate from countries where the second demographic transition (Lesthaeghe 2010) has not occurred or not to the same extent as in the host countries. At the same time, immigration from these countries to EU countries is restricted by visa regulations; and thus marriage or family migration may be the only way to immigrate. Therefore, a high share of married persons in the first generation and accordingly a high share of marital births do not tell us much about a continuation of culture because it is highly intertwined with migration policies. In the second and third generations, marriage and marital childbearing may be rather an indicator of cultural maintenance, at least in the cases where no transnational marriage-migration is involved. Some groups (e.g., UK-born Pakistanis and Bangladeshis in the United Kingdom) continue to marry someone from overseas and hence migration remains associated with marriage (see Berrington 2018). Moreover, the ethnicity of the partner (endogamy versus a mixed marriage) may be crucial for fertility behaviour (Milewski 2010b, van Landschoot et al. 2017). Here, the question to be asked relates to the role of causality between marriage type and fertility and the selection into a mixed marriage.

Third, higher education is generally perceived as the driving force for innovation and new (demographic) behaviour. Therefore, also in the field of migrant fertility, the higher educated should receive specific attention, instead of using education as a sole control variable for compositional differences between groups. We can conclude from papers in this SC that higher educated immigrants show a faster adaptation to natives' fertility patterns - the question remains, however, if they adapted their behaviour primarily to the economic situation and welfare-policy context, or if these changes were accompanied by acculturation processes. Such acculturation would be measurable if the ideational dimensions of fertility (such as intentions, preferences, and ideal family size) were to be included in the analysis (Holland and de Valk 2013).

Fourth, childlessness among immigrants and their descendants may deserve special attention. The share of immigrants in the first generation who remain childless is generally rather low (often no more than $5 \%$ ) because of selection into migration due to marriage. One of the main differences in fertility between the European receiving countries and the countries of origin of the migrants is not only the higher parities but also the levels of childlessness. In some Western European countries, the proportion of childless women is as high as $20 \%$ (Kulu and Hannemann 2016). In other areas of the world, where familialism is more common, religiosity is stronger, and gender equality is lower, the prestige of a woman is largely related to her motherhood status. Western countries may offer more and competing opportunities for immigrant women (besides barriers to structural integration). Hence, will migrant descendants be better able to combine fertility and labour force participation, or will they have to decide between two options? 
To summarise, the papers of this SC show a significant heterogeneity in fertility behaviour among descendants of immigrants. Some descendant groups have fertility levels similar to those of natives, some have lower fertility, and some still exhibit significantly higher fertility. Additionally, polarisation characterises some descendant groups; some individuals have small families or even remain childless, whereas others have large families. Future research should investigate whether this heterogeneity is temporary and expected to decline over time and generations or the diversity is here to stay.

\section{Acknowledgements}

The research leading to these results has received funding from the European Union's Seventh Framework Programme (FP7/2007- 2013) under grant agreement no. 320116 for the research project FamiliesAndSocieties. Hill Kulu and Júlia Mikolai's work was also supported by Economic and Social Research Council grant ES/K007394/1 and carried out in the ESRC Centre for Population Change (CPC).

The authors are grateful to Alícia Adserà, Gunnar Andersson, Ann Berrington, Allan Puur, Tomáš Sobotka, two anonymous referees, and the editor of Demographic Research for valuable comments and suggestions on a previous version of this paper.

The data used in this study is from Understanding Society: The UK Household Longitudinal Study, which is conducted by the Institute for Social and Economic Research at the University of Essex and funded by the Economic and Social Research Council. Information on how to access the data can be found on the Understanding Society website https://www.understanding society.ac.uk/. 


\section{References}

Adserà, A. and Ferrer, A. (2015). Immigrants and demography: Marriage, divorce, and fertility. In: Chiswick, B.R. and Miller, P.W. (eds.). Handbook of the economics of international migration. Oxford and Amsterdam: Elsevier: 315-374.

Alba, R.D. and Foner, N. (2015). Strangers no more. Immigration and the challenges of integration in North America and Western Europe. Princeton: Princeton University Press.

Alba, R.D. and Nee, V. (2003). Remaking the American mainstream: Assimilation and contemporary America. Cambridge: Harvard University Press. doi:10.4159/978 0674020115.

Andersson, G. (2004). Childbearing after migration: Fertility patterns of foreign-born women in Sweden. International Migration Review 38(2): 747-774. doi:10.1111/j.1747-7379.2004.tb00216.x.

Andersson, G., Persson, L., and Obućina, O. (2017). Depressed fertility among descendants of immigrants in Sweden. Demographic Research 36(39): 11491184. doi:10.4054/DemRes.2017.36.39.

Baykara-Krumme, H. and Milewski, N. (2017). Fertility patterns among Turkish women in Turkey and abroad: The effects of international mobility, migrant generation, and family background. European Journal of Population 33(3): 409436. doi:10.1007/s10680-017-9413-9.

Bean, F.D. and Tienda, M. (1990). The Hispanic population of the United States. New York: Russell Sage Foundation.

Berrington, A. (2018). Expectations for family transitions in young adulthood among the UK second generation. Journal of Ethnic and Migration Studies (online first). doi:10.1080/1369183X.2018.1539276.

Bourdieu, P. (1977). Outline of a theory of practice. Cambridge: Cambridge University Press. doi:10.1017/CBO9780511812507.

Castro-Martín, T. and Rosero-Bixby, L. (2011). Motherhood and transnational borders: Immigrants' women fertility in Spain. Revista Internacional De Sociologia 69: $105-137$.

Coleman, D.A. (1994). Trends in fertility and intermarriage among immigrant populations in Western-Europe as measure of integration. Journal of Biosocial Science 26(1): 107-136. doi:10.1017/S0021932000021106. 
Coleman, D.A. (2006). Immigration and ethnic change in low-fertility countries: A third demographic transition. Population and Development Review 32(3): 401446. doi:10.1111/j.1728-4457.2006.00131.x.

Coleman, D.A. and Dubuc, S. (2010). The fertility of ethnic minorities in the UK, 1960s-2006. Population Studies 64(1): 19-41. doi:10.1080/003247209033912 01.

Dribe, M. and Lundh, C. (2012). Intermarriage, value context and union dissolution: Sweden 1990-2005. European Journal of Population 28(2): 139-158. doi:10.1007/s10680-011-9253-y.

Dupray, A. and Pailhé, A. (2018). Does employment uncertainty particularly impact fertility of children of North African immigrants in France? A gender perspective. Journal of Ethnic and Migration Studies 44(3): 401-424. doi:10.1080/1369183X.2017.1313107.

Elster, J. (1989). Nuts and bolts for the social sciences. Cambridge: Cambridge University Press. doi:10.1017/CBO9780511812255.

Foner, N. (1997). The immigrant family: Cultural legacies and cultural changes. International Migration Review 31(4): 961-975. doi:10.1177/01979183970310 0407.

Giddens, A. (1984). The constitution of society: Outline of the theory of structuration. Cambridge: Polity Press.

Giele, J.Z. and Elder, G.H.J. (1998). Methods of life course research: Qualitative and quantitative approaches. Thousand Oaks: Sage Publications. doi:10.4135/ 9781483348919.

Goldscheider, F., Goldscheider, C., and Bernhardt, E.M. (2011). Creating egalitarian families among the adult children of Turkish- and Polish-origin immigrants in Sweden. International Migration Review 45(1): 68-88. doi:10.1111/j.17477379.2010.00839.x.

González-Ferrer, A. (2006). Why do immigrants marry? Partner choice among single immigrants in Germany. European Sociological Review 22(2): 171-185. doi:10.1093/esr/jci050.

González-Ferrer, A., Castro-Martín, T., Kraus, E.K., and Eremenko, T. (2017). Childbearing patterns among immigrant women and their daughters in Spain: Over-adaptation or structural constraints? Demographic Research 37(19): 599634. doi:10.4054/DemRes.2017.37.19. 
Kulu et al.: A decade of life-course research on fertility of immigrants and their descendants in Europe

Gordon, M. (1964). Assimilation in American life. New York: Oxford University Press.

Guarin Rojas, E.A., Bernardi, L., and Schmid, F. (2018). First and second births among immigrants and their descendants in Switzerland. Demographic Research 38(11): 247-286. doi:10.4054/DemRes.2018.38.11.

Haug, W. (2000). National and immigrant minorities: Problems of measurement and definition. Genus 56(1-2): 133-147.

Hinde, A. (1998). Demographic methods. London: Arnold.

Hoem, J.M. (1975). Fertility and out-migration: Reflections on research approaches in empirical investigations of the association between two demographic phenomena. Copenhagen: University of Copenhagen.

Hoem, J.M. (1990). Social policy and recent fertility change in Sweden. Population and Development Review 16(4): 735-748. doi:10.2307/1972965.

Hoem, J.M. (1993). Public policy as the fuel of fertility: Effects of a policy reform on the pace of childbearing in Sweden in the 1980s. Acta Sociologica 36(1): 19-31. doi:10.1177/000169939303600102.

Hoem, J.M. and Mureşan, C. (2011). The total marital fertility rate and its extensions. European Journal of Population 27(3): 295-312. doi:10.1007/s10680-011-9237y.

Holland, J.A. and de Valk, H.A.G. (2013). Ideal ages for family formation among immigrants in Europe. Advances in Life Course Research 18(4): 257-269. doi:10.1016/j.alcr.2013.08.002.

Hollis, M. (1996). Philosophy of social science. In: Bunnin, N. and Tsui-James, E.P. (eds.). The Blackwell companion to philosophy. Oxford: Blackwell Publishers: 358-387.

Kalmijn, M. and Kraaykamp, G. (2018). Determinants of cultural assimilation in the second generation. A longitudinal analysis of values about marriage and sexuality among Moroccan and Turkish migrants. Journal of Ethnic and Migration Studies 44(5): 697-717. doi:10.1080/1369183X.2017.1363644.

Kalmijn, M. and van Tubergen, T. (2006). Ethnic intermarriage in the Netherlands: Confirmations and refutations of accepted insights. European Journal of Population 22(4): 371-397. doi:10.1007/s10680-006-9105-3.

Kennedy, R.E. (1973). The Irish: Emigration, marriage, and fertility. Berkeley: University of California Press. 
Khlat, M. and Darmon, N. (2003). Is there a Mediterranean migrants mortality paradox in Europe? International Journal of Epidemiology 32(6): 1115-1118. doi:10.1093/ije/dyg308.

Kibele, E., Scholz, R., and Shkolnikov, V.M. (2008). Low migrant mortality in Germany for men aged 65 and older: Fact or artifact? European Journal of Epidemiology 23(6): 389-393. doi:10.1007/s10654-008-9247-1.

Krapf, S. and Wolf, K. (2015). Persisting differences or adaptation to German fertility patterns? First and second birth behavior of the 1.5 and second generation Turkish migrants in Germany. Kölner Zeitschrift für Soziologie und Sozialpsychologie 67(1): 137-164. doi:10.1007/s11577-015-0331-8.

Kulu, H. (2005). Migration and fertility: Competing hypotheses re-examined. European Journal of Population 21(1): 51-87. doi:10.1007/s10680-005-3581-8.

Kulu, H. and González-Ferrer, A. (2014). Family dynamics among immigrants and their descendants in Europe: Current research and opportunities. European Journal of Population 30(4): 411-435. doi:10.1007/s10680-014-9322-0.

Kulu, H. and Hannemann, T. (2016). Why does fertility remain high among certain UKborn ethnic minority women? Demographic Research 35(49): 1441-1488. doi:10.4054/DemRes.2016.35.49.

Kulu, H., Hannemann, T., Pailhé, A., Neels, K., Krapf, S., González-Ferrer, A., and Andersson, G. (2017). Fertility by birth order among the descendants of immigrants in selected European countries. Population and Development Review 43(1): 31-60. doi:10.4054/DemRes.2016.35.49.

Kulu, H. and Milewski, N. (2007). Family change and migration in the life course: An introduction. Demographic Research 17(19): 567-590. doi:10.4054/DemRes. 2007.17.19.

Lesthaeghe, R. (2010). The unfolding story of the Second Demographic Transition. Population and Development Review 36(2): 211-251. doi:10.1111/j.1728-4457. 2010.00328.x.

Lillehagen, M. and Lyngstad, T.H. (2018). Immigrant mothers' preferences for children's sexes: A register-based study of fertility behaviour in Norway. Population Studies 72(1): 91-107. doi:10.1080/00324728.2017.1421254.

Macisco, J.J., Bouvier, L.F., and Weller, R.H. (1970). Effect of labour force participation on relation between migration status and fertility in San Juan, 
Kulu et al.: A decade of life-course research on fertility of immigrants and their descendants in Europe

Puerto Rico. The Milbank Memorial Fund Quarterly 48(1): 51-70. doi: $10.2307 / 3349288$.

Mayer, J. and Riphahn, R.T. (2000). Fertility assimilation of immigrants: Evidence from count data models. Journal of Population Economics 13(2): 241-261. doi:10.1007/s001480050136.

Milewski, N. (2007). First child of immigrant workers and their descendants in West Germany: Interrelation of events, disruption, or adaptation? Demographic Research 17(29): 859-896. doi:10.4054/DemRes.2007.17.29.

Milewski, N. (2010a). Immigrant fertility in West Germany: Is there a socialization effect in transitions to second and third births? European Journal of Population 26(3): 297-323. doi:10.1007/s10680-010-9211-0.

Milewski, N. (2010b). Fertility of immigrants. A two-generational approach in Germany. Demographic Research Monographs. Hamburg: Springer.

Milewski, N. (2011). Transition to a first birth among Turkish second-generation migrants in Western Europe. Advances in Life Course Research 16(4): 178-189. doi:10.1016/j.alcr.2011.09.002.

Milewski, N. and Kulu, H. (2014). Mixed marriages in Germany: A high risk divorce for immigrant-native couples. European Journal of Population 30(1): 89-113. doi:10.1007/s10680-013-9298-1.

Mulder, C.H. and Wagner, M. (2001). The connections between family formation and first-time home ownership in the context of West Germany and the Netherlands. European Journal of Population 17(2): 137-164. doi:10.1023/A:1010706308 868.

Murphy, M. (2016). Migrant total fertility rates: Time for a rethink? Paper presented at the Annual Meeting of the British Society for Population Studies, Winchester, UK, September 12-14, 2016.

Mussino, E., Gabrielli, G., Paterno, A., Strozza, S., and Terzera, L. (2015). Motherhood of foreign women in Lombardy: Testing the effects of migration by citizenship. Demographic Research 33(23): 653-664. doi:10.4054/DemRes.2015.33.23.

Mussino, E. and Strozza, S. (2012a). The fertility of immigrants after arrival: The Italian case. Demographic Research 26(4): 97-130. doi:10.4054/DemRes. 2012.26.4. 
Mussino, E. and Strozza, S. (2012b). Does citizenship still matter? Second birth risks of migrants from Albania, Morocco, and Romania in Italy. European Journal of Population 28(3): 269-302. doi:10.1007/s10680-012-9261-6.

Pailhé, A. (2017). The convergence of second-generation immigrants' fertility patterns in France: The role of sociocultural distance between parents' and host country. Demographic Research 36(45): 1361-1398. doi:10.4054/DemRes.2017.36.45.

Persson, L. and Hoem, J.M. (2014). Immigrant fertility in Sweden, 2000-2011: A descriptive note. Demographic Research 30(30): 887-897. doi:10.4054/Dem Res.2014.30.30.

Poston, D.L., Chang, C.F., and Dan, H. (2006). Fertility differences between the majority and minority nationality groups in China. Population Research and Policy Review 25(1): 67-101.

Puur, A., Rahnu, L., Abuladze, L., Sakkeus, L., and Zakharov, S. (2017). Childbearing among first- and second-generation Russians in Estonia against the background of the sending and host countries. Demographic Research 36(41): 1209-1254. doi:10.4054/DemRes.2017.36.41.

Robards, J. and Berrington, A. (2016). The fertility of recent migrants to England and Wales. Demographic Research 34(36): 1037-1052. doi:10.4054/DemRes. 2016.34.36.

Scott, K. and Stanfors, M. (2011). The transition to parenthood among the second generation: Evidence from Sweden, 1990-2005. Advances in Life Course Research 16(4): 190-204. doi:10.1016/j.alcr.2011.09.003.

Simon, P. (2008). The choice of ignorance: The debate on ethnic and racial statistics in France. French Politics. Culture \& Society 26: 7-31. doi:10.3167/fpcs.2008. 260102.

Simon, P. and Piché, V. (2012). Accounting for ethnic and racial diversity: The challenge of enumeration. Ethnic and Racial Studies 35(8): 1357-1365. doi:10.1080/01419870.2011.634508.

Singley, S.G. and Landale, N.S. (1998). Incorporating origin and process in migrationfertility frameworks: The case of Puerto Rican women. Social Forces 76(4): 1437-1464. doi:10.1093/sf/76.4.1437.

Sobotka, T. (2008). The rising importance of migrants for childbearing in Europe. Demographic Research 19(9): 225-247. doi:10.4054/DemRes.2008.19.9. 
Sole-Auro, A. and Crimmins, E.M. (2008). Health of immigrants in European countries. International Migration Review 42(4): 861-876. doi:10.1111/j.17477379.2008.00150.x.

Toulemon, L. (2004). Fertility among immigrant women: New data, a new approach. Population and Societies 400: 1-4.

University of Essex. Institute for Social and Economic Research, NatCen Social Research, Kantar Public. (2018). Understanding Society: Waves 1-7, 20092016 and Harmonised BHPS: Waves 1-18, 1991-2009. [data collection]. $10^{\text {th }}$ Edition. UK Data Service. SN: 6614.

van Landschoot, L., de Valk, H.A.G., and Van Bavel, J. (2017). Fertility among descendants of immigrants in Belgium: The role of the partner. Demographic Research 36(60): 1827-1858. doi:10.4054/DemRes.2017.36.60.

Vertovec, S. (2004). Migrant transnationalism and modes of transformation. International Migration Review 38(3): 970-1001. doi:10.1111/j.1747-7379. 2004.tb00226.x.

Wilson, B. and Kuha, J. (2018). Residential segregation and the fertility of immigrants and their descendants. Population, Space and Place 24(3): e2098. doi:10.1002/ psp.2098. 